\title{
Study on Cross-Cultural Adaptability of Students of Articulation Program-Taking Chinese Students Studying Abroad at Harding University in the US as an Example
}

\author{
Risheng Zhong, Yuanyuan Chen, Di Wang, Feng Xiao* \\ Guangdong University of Foreign Studies, Guangzhou, China \\ Email: *xiaofeng@gdufs.edu.cn
}

How to cite this paper: Zhong, R. S., Chen, Y. Y., Wang, D., \& Xiao, F. (2020). Study on Cross-Cultural Adaptability of Students of Articulation Program-Taking Chinese Students Studying Abroad at Harding University in the US as an Example. Open Journal of Social Sciences, 8, 56-70.

https://doi.org/10.4236/jss.2020.812006

Received: November 11, 2020

Accepted: December 6, 2020

Published: December 9, 2020

Copyright $\odot 2020$ by author(s) and Scientific Research Publishing Inc. This work is licensed under the Creative Commons Attribution International License (CC BY 4.0).

http://creativecommons.org/licenses/by/4.0/

\begin{abstract}
Students of articulation program will inevitably encounter various cultural adaptation problems when studying abroad. This study takes students studying abroad at Harding University in the United States as a sample to explore the cross-cultural adaptation of students studying abroad, focuses on the cross-cultural adaptability problems encountered by students in study and life while studying in the United States, and uses questionnaires to investigate the level of cross-cultural adaptability. The researchers put forward some suggestions for improving the level of students' cross-cultural adaptation.
\end{abstract}

\section{Keywords}

Articulation Program, Chinese Students, Cross-Cultural Adaptation, American Universities

\section{Introduction}

Articulation program refers to education and teaching activities that Chinese higher education institutions and foreign higher education institutions cooperate in disciplines, majors, and courses without setting up educational institutions. After studying in a Chinese university for two years and meeting the corresponding academic standards, students go to the United States to complete the remaining two years of undergraduate course study tasks, and finally obtain a degree from an American university. This is currently the main form of Sino-foreign cooperation in running schools in Chinese universities, and has shown a trend of rapid development in recent years. After students enter the 
United States to study, due to the huge differences in education mode, living environment, and interpersonal relationships, Chinese students face huge difficulties in cross-cultural adaptation (Tan, 2013). These difficulties include language difficulties, changes in learning styles, academic pressures, climate and dietary discomforts, changes in communication styles, and various difficulties caused by cultural differences, as well as the prejudices and discrimination encountered or perceived due to the imbalance between Chinese and foreign cultures. Discrimination will largely affect students' learning and living conditions in the new cultural environment. Their acceptance and adaptation to the culture of the country where they study abroad and their awareness of traditional Chinese culture have a very important impact on their academic achievements, mental health, and personal development.

In the research on the cultural adaptability of Chinese students abroad, there are few references available abroad. The Council for International Education conducted a large-scale study on international students in 2004. Through a survey of 4796 international students, they conducted surveys on their learning situation, concerns, leisure and entertainment, difficulties, etc., to understand how international students performed in cross-cultural adaptation.

In the article Patterns of Adaptation of Chinese Postgraduate Students in the United Kingdom, Zhou, Y. and Todman, J. conducted a questionnaire survey on 257 Chinese postgraduate students in the United Kingdom. 28 students were selected for in-depth interviews to explore the cultural adaptation of students under different modes of going abroad (Zhou \& Todman, 2009). At present, there is still a lack of research results on cross-cultural adaptation of systematic and in-depth tracking and interviews with Chinese students abroad, and it is difficult to provide a large number of ready-made research results for research reference.

Researchers conducted a survey on the cross-cultural adaptability of students from the Harding University Articulation Program of Guangdong University of Foreign Studies in the form of self-compiled questionnaires. This study uses the perspective of cross-cultural psychology of Chinese students in the United States to study their cross-cultural adaptation and adopts the means of data analysis to make descriptive statistics and analysis of the data obtained from the questionnaire survey to fully understand the cross-cultural adaptation issues of the current study abroad training program students.

\section{Research Method}

\subsection{Research Design}

The researcher conducted semi-open interviews with 17 students of Harding University coming from Guangdong University of Foreign Studies. In the interview, students were asked about events that affect their cross-cultural adaptation, based on which inductive analysis was conducted and core keywords were extracted. The interview used "rooted theory" methods to encode keywords. Fi${ }^{1}$ Broadening Our Horizons: International Students in UK Universities and Colleges. UKCOSA The council for International Education. 2004. 
nally, four first-level codes were extracted, namely "social culture", "interpersonal relationship", "environmental factors" and "academic situation". Researchers designed 29 questions around these four factors and used Likert's 5-point method. The compiled questionnaire is named "Questionnaire on Cross-cultural Adaptability of Chinese Students Studying Abroad Training Program in the United States" (hereinafter referred to as the Questionnaire).

\subsection{Research Process}

The researcher distributed the survey questionnaire to Chinese students from various Chinese universities studying in Harding University. A total of 65 students were surveyed, accounting for $39 \%$ of the total number of Chinese students in Harding University. In this survey, 65 questionnaires were sent out and 65 valid questionnaires were returned, with a recovery rate of $100 \%$.

\section{Analysis on Cross-Cultural Adaption}

After arriving in the United States, students have generally adapted well. Factors such as the length of staying in the United States and the level of language foundation are positively correlated with the degree of cross-cultural adaptation.

\subsection{Social Culture}

Social culture is composed of multiple factors such as religious beliefs, mainstream social values, and legal systems. Because students lack the support of the original cultural system, and at the same time, the negative experience in the new cultural context makes them suffer a lot of anxiety and frustration (Xie, 2013).

\subsubsection{Belief}

Harding University in the United States is a well-known church school with biblical character education and the principles of life being its highest teaching goals. The study of professional knowledge is only a means to serve the society and help others after obtaining "perfect character education". Harding University has no requirements for students' beliefs, but it attaches great importance to the education of Christian thought. It requires all students to participate in Chapel (an activity that promotes Christian ideas) every day, assigns two staff members to be responsible for attendance work, and demands all students take Bible course. However, while answering the four questions: "I like to read the Bible", "I believe in the stories in the Bible", "I will take the initiative to share the stories in the Bible with others and discuss them", and "I will often participate in church activities" with options of "strongly disagree", "disagree" and "general" for the question, the sum of the three options reached $82.76 \%$ (Figure 1), $82.76 \%$ (Figure 2), 87.93\% (Figure 3) and $87.93 \%$ (Figure 4). It shows that the students are not affected by religious education. In the subsequent interviews, it was found that the students did not believe in and agreed with Christian ideas, and 


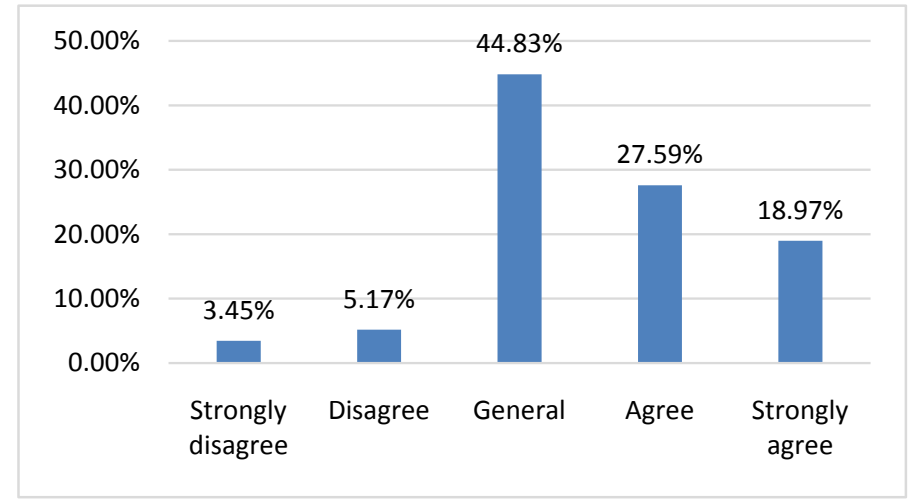

Figure 1. I like to read the Bible.

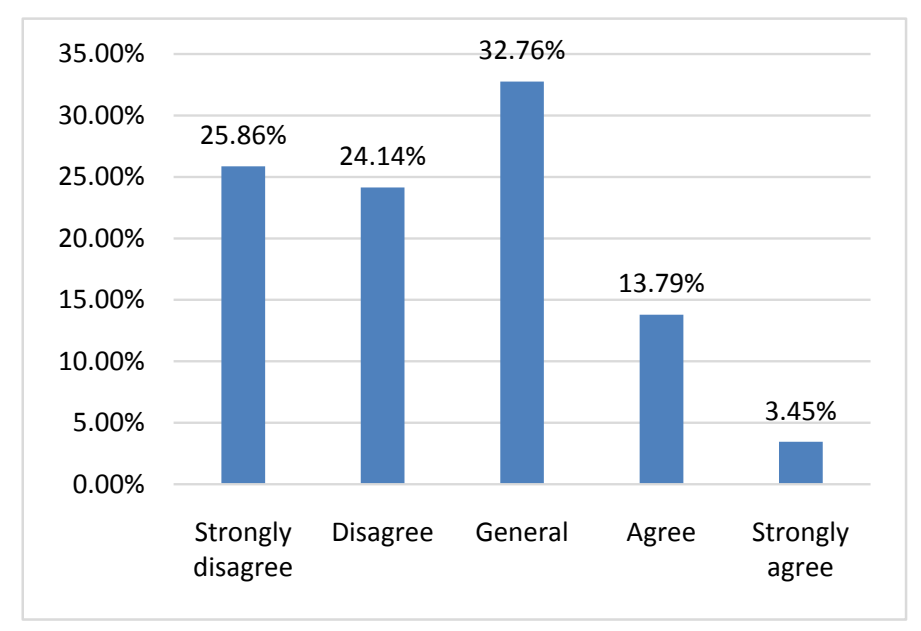

Figure 2. I believe in the stories in the Bible.

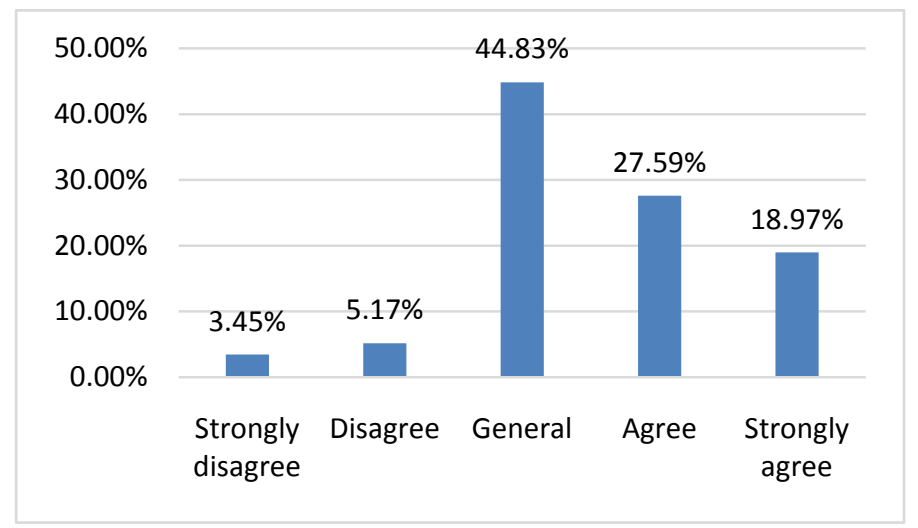

Figure 3. I will take the initiative to share the stories in the Bible with others and discuss them.

took the "Bible" class just to complete the credits of the required courses, which reveals that the effect of Chinese students receiving materialism education and ideological and political education for many years is remarkable. They do not agree with the doctrine of Christianity, and they have not abandoned their original ideals and beliefs because of entering a new cultural environment. 


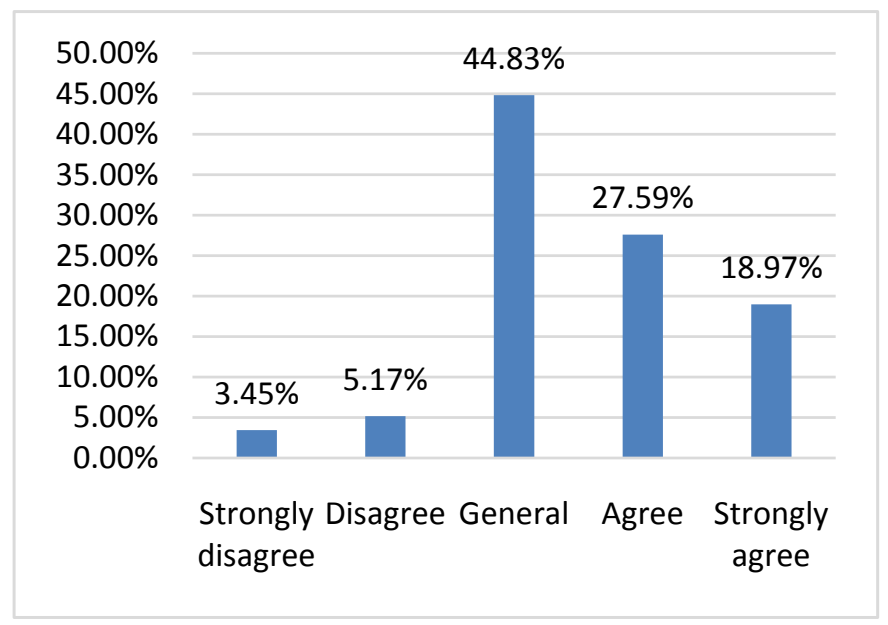

Figure 4. I will often participate in church activities.

\subsubsection{Social Order}

Most students said that they soon adapted to the American social order and behavioral norms after arriving in the United States. They liked the American culture of queuing and comity very much, which they easily internalized into their own behavior.

Students know that America is a society ruled by law. Because of their unfamiliarity with the public power system, Chinese students can abide by American laws and university systems better than American students in daily life and study. In the interview, the students mentioned that although American students sometimes feel that Chinese students are too cautious, the notion of "It is better to believe in what is than to believe in what is not" makes them strictly abide by American laws and school systems (Wang, 2012).

\subsection{Interpersonal Relationship}

\subsubsection{Circle of Friends}

$74.14 \%$ (Figure 5) of the students interviewed chose to live with Chinese, 70.69\% (Figure 6) thought they had more American friends, and 63.79\% (Figure 7) often participated in activities together with American friends.

Interview records show that the social interaction of Chinese students studying in the United States is mainly within the Chinese social circle. The students interviewed said that it is difficult to have more contact with Americans. Becoming good friends with Americans and successfully communicating with Americans are the two most difficult social things to accomplish, and the communication difficulties are attributed to the cultural gap between China and the United States. Language barriers have caused serious cultural confusion among foreign students in the United States. Their general lack of appropriate language skills has led to a greater sense of social separation. Another situation is that international students lack American friends of the same age while studying in the United States, which upsets them most. As one student pointed out: "Although I have many opportunities to meet American peers on American campuses, there 


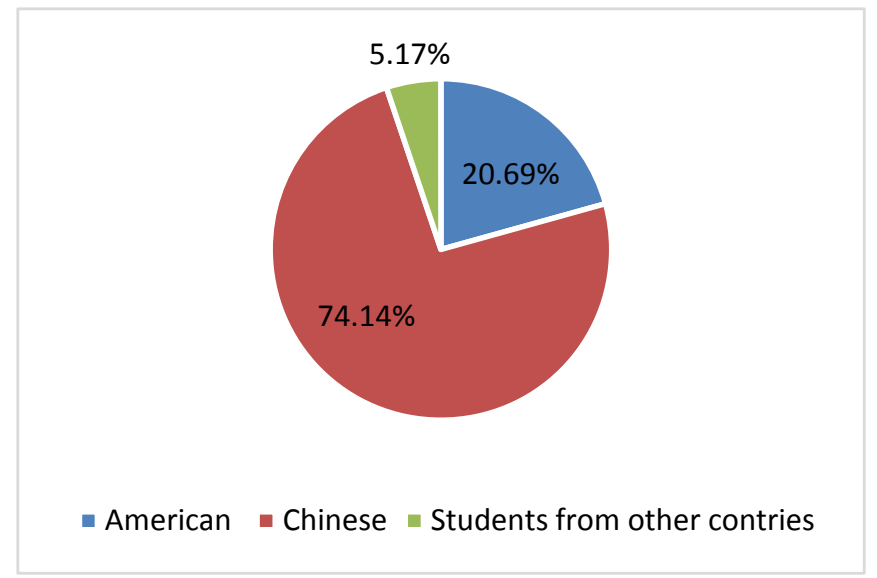

Figure 5. Where are your roommates from?

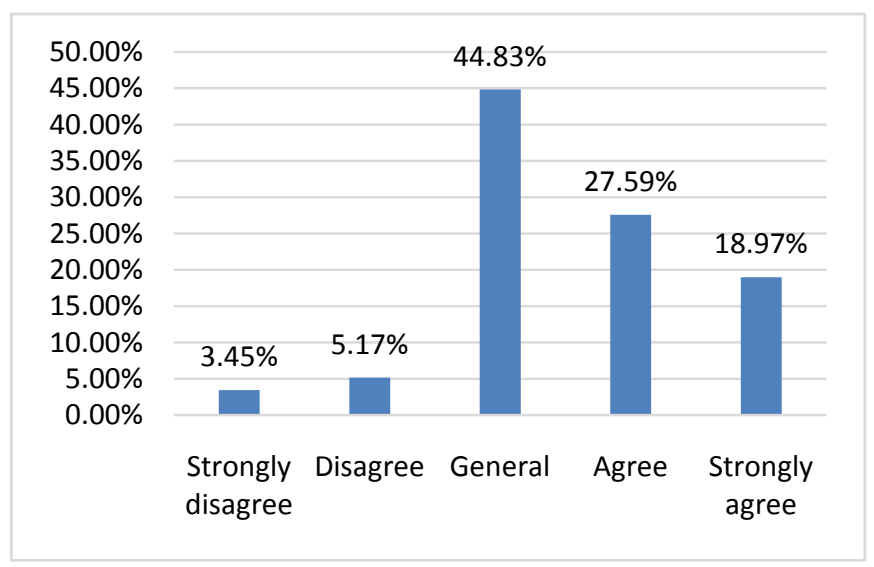

Figure 6. I have more American friends.

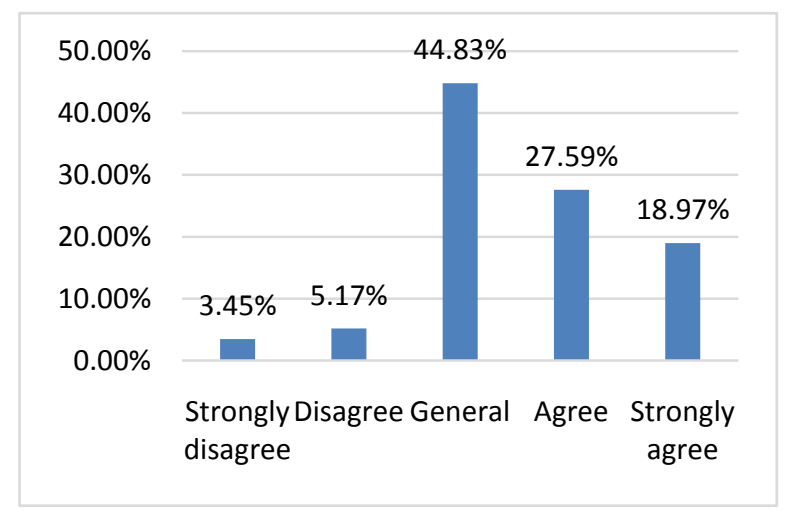

Figure 7. I often participated in activities together with American friends.

are very few real effective social interactions." The old social connections are difficult to sustain due to geographical and time differences, while the new social connections are difficult to establish in a short time. Students generally feel lonely and anxious because of the lack of effective social communication.

Even if the students who participated in the interview realized that limiting themselves to the circle of friends of Chinese students while avoiding contact 
with American classmates will create more separation with American society and culture, which will affect the language improvement and cultural adjustment in the United States, but because their emotional and social needs have been well met by the Chinese student circle, so Chinese students rarely take the initiative to interact with Americans.

\subsubsection{Class and Small Group Organization Structure}

Interviewed international students believe that there are objective reasons why it is difficult for them to have deep communication with locals. Compared with the fixed class structure of Chinese colleges and universities, the loose organizational structure of Western colleges and universities allows Chinese students to interact with local students in the classroom, and there are not many occasions for their interaction after class.

Another influencing factor that cannot be ignored is related to the characteristics of the articulation program, which is favored because students have completed two years of study in China, and the students in the same class will be arranged to the same program and major. Since they are familiar with each other, they continue to study in the same major in the same college after going abroad, and many of them also choose to live together. There is also the help of senior students who have already met in China and came to the United States to study in the United States a year earlier. Therefore, they play an important role in each other's social support network, giving each other emotional, material and information support and help. However, there are more and more seniors and younger brothers and sisters who are studying for undergraduates and masters in a school, and they gather most of the time, reducing the opportunities for foreign students to interact and contact with locals.

\subsubsection{Teacher-Student Relationship}

The international students of the articulation program generally agree with the academic level of foreign university teachers and respect the teaching attitude of students expressing personal opinions on classroom issues. However, they are reluctant to discuss with students issues other than learning. That's different from the attitude of counselor and class teacher when studying in China. Some students said that although American teachers feel more equal compared with domestic teachers, the relationship between teachers and students is not as close as in China.

\subsection{Environmental Factors}

\subsubsection{Development after Graduation}

$55.17 \%$ (Figure 8) students intend to stay and work in the United States after graduation. In the past, most Chinese students who graduated from the United States would strive to stay in the United States to work and live. However, in recent years, due to the rapid development of China's economy and the significant improvement of China's status in the world, international students have gradually shaken up whether to stay in the United States after graduation. The vacillation 


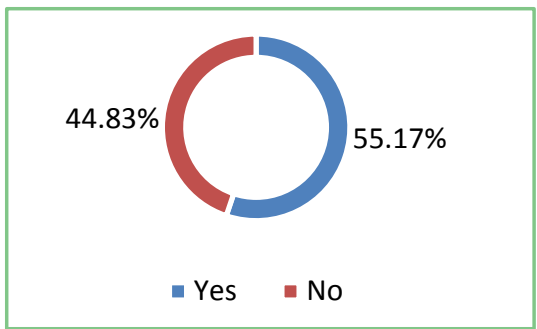

Figure 8. Would you stay and work in the United States after graduation?

of the mentality of studying in the U.S. is caused by three factors: the number of Chinese graduates graduating in the U.S. has increased sharply, while employment opportunities in the U.S. have been relatively slow; U.S. economic development is not strong enough; excessive expectations and lack of work experience. The unclear job prospects make Chinese students hesitant to study in the United States.

\subsubsection{Food}

68.97\% (Figure 9) of the students said they did not like the food in the American university canteen, while $96.55 \%$ (Figure 10) of the students thought that they would be very happy if they could eat Chinese food.

Food is the biggest life difficulty faced by Chinese students studying abroad. Although Chinese students agree with the clean and tidy sanitary conditions of American dining halls, they are not used to the combination of various breads and potatoes. It is found that the life satisfaction and adaptability of students who can cook are generally higher than those who eat in the canteen, and they can also focus on adapting to learning styles. The family conditions of overseas students who can go abroad are relatively superior. Most families only focus on academic performance and ignore the exercise of living ability. When the students left their family to go abroad, they found that all things can only be done by themselves, although they also enjoyed it. In China, parents take care of most of the daily chores, and students can only obey their parents' opinions; while in the United States, they can take charge of everything. In interviews, students said that they had the feeling of "finally feel in charge of the house".

\subsubsection{Accommodation}

Compared with domestic college dormitories, American college dormitories have superior hardware facilities, and American-style humanized management and thoughtful service make students enjoy it. 96.55\% (Figure 11) of the students said they prefer the dormitory environment of American colleges and universities, and $70.69 \%$ (Figure 12) of the students said they prefer the dormitory management mode of American colleges and universities.

\subsection{Academic Situation}

\subsubsection{Academic Pressure}

In the interview, Chinese students mentioned that the Chinese family and the 


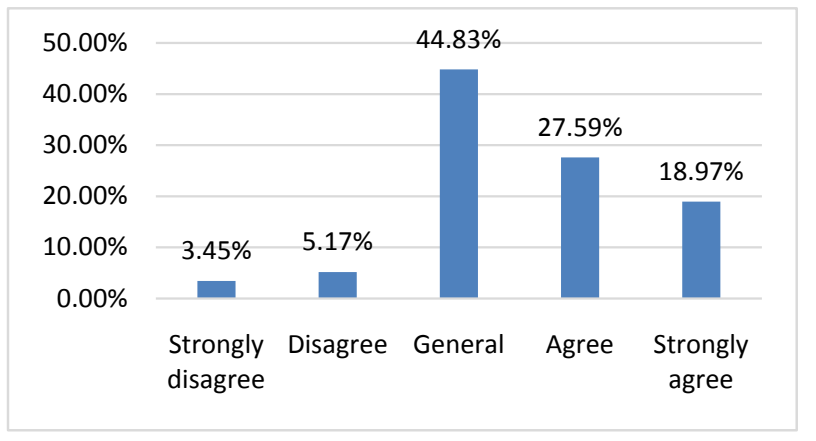

Figure 9. I like the food in American university.

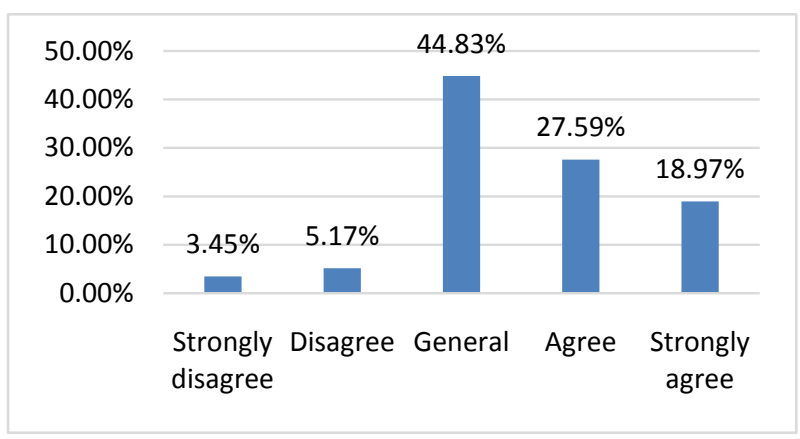

Figure 10. I will be very happy if I could eat Chinese food.

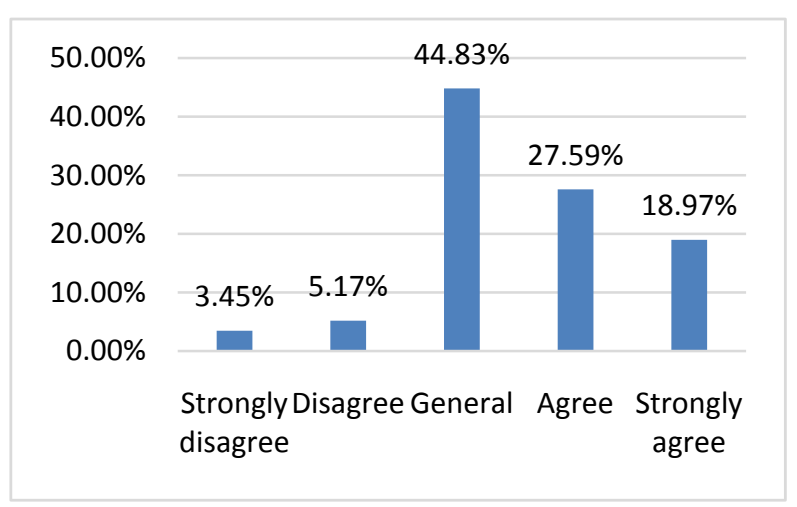

Figure 11. I like my accommodation environment.

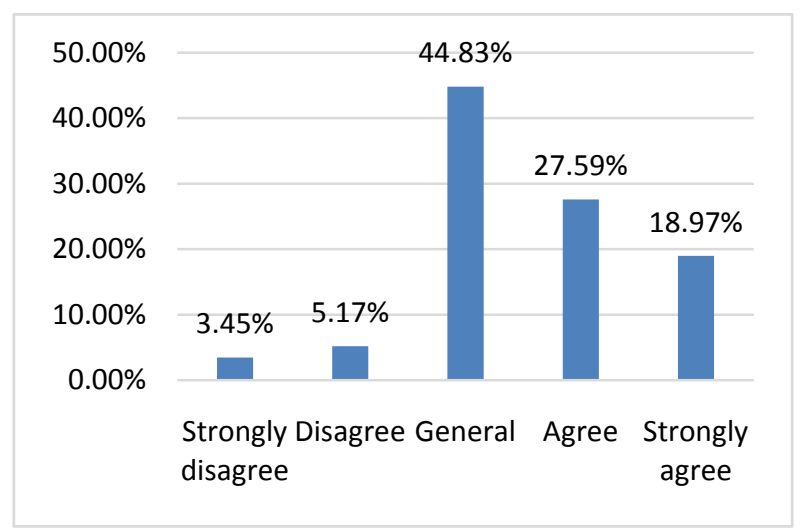

Figure 12. I prefer American-style accommodation management than that of China. 
traditional culture emphasizing much on education increase great pressure to them, forcing them to constantly put pressure on themselves to complete their studies smoothly and successfully. In the eyes of parents, students are the future and hope of the family, and the whole family has poured a lot of manpower, material resources and financial resources into the students' academic work. Parents generally hope that students can return to their homeland as soon as possible. In addition, students in China generally believe that an American degree is a strong guarantee for their future social and career development in China or the United States.

The interview records also show that there are three factors that determine whether Chinese students are successful in their studies in the United States: whether they can adapt to the American educational environment; whether they can overcome language barriers in a short period of time; whether they have a good teacher-student relationship. The cultivation of self-discipline and autonomy of the interviewed Chinese students is the biggest challenge that American education poses to them. For most Chinese students who are accustomed to exam-oriented education, the self-development of American education is not so easy to adapt (Yan, 2011).

In addition, language barriers and communication problems also cause great academic pressure on students. The lack of necessary knowledge of the context and cultural background, lack of adequate opportunities for English practice, and lack of hard work in learning English in China have caused language problems to affect the improvement of academic standards (Eura et al., 2007).

A large majority of participants mentioned that the purpose of studying English in China is only to pass the IELTS or TOEFL test. The highly targeted test-taking training makes it difficult for Chinese students to use English to communicate academically and socially with teachers and classmates in American colleges and universities after enrolling in the United States.

\subsubsection{Classroom Learning}

Although the students of the articulation program have learned a series of intensive English courses in the domestic study stage, and have reached the IELTS or TOEFL test requirements required by foreign institutions, they generally think that their English ability is still not able to fully understand the content of the teacher's lecture or conduct class discussions with Americans. They believe that the foreign language training at the domestic learning stage mainly focuses on the reading and writing required by college English, and lacks training in daily oral expression and academic English. Fortunately, because most of the students have a good foundation in English, it does not appear that they can barely understand the course content after going abroad.

Another reason why students in the articulation program can't fully understand the teaching content and fully participate in classroom discussions is that they are not adapted to American teaching methods. The American teaching method emphasizes students' autonomous learning ability and critical thinking 
(Lewthwaite, 1997). The students acknowledged that such an open teaching method helps to diverge thinking and improve the subjective initiative of learning, but it has changed from "mainly teaching by teachers and passive learning by students" to "mainly academic discussion, advocating questioning and questioning". The classroom learning atmosphere makes them feel more pressure in classroom learning. Unlike Western society, which emphasizes self-expression and encourages individuality, the education that Chinese students receive from an early age is centered on collective interests. At the same time, the modesty and restraint in traditional Chinese cultural thoughts also have a greater impact on students. Therefore, facing the question of "should I ask questions in class", students think more about whether my questioning will affect the learning of the whole class and the teacher's teaching ideas. In opposite, American students pay more attention to ability to solve personal practical problems and self-expression.

\subsubsection{Course Requirements}

In terms of course requirements, the international students believe that there are more group assignments, more oral presentations, and more essay writing. They think that the lack of language proficiency, critical thinking and cross-cultural communication skills are the three biggest factors affecting them. Moreover, most foreign universities attach importance to teamwork among students. Foreign universities believe that information exchange, academic debate and knowledge sharing among students are effective ways to help them improve their thinking ability and academic level.

\subsection{Overall Experience and Personal Gains of Studying Abroad}

77.59\% (Figure 13) of the students said they are happy every day in the United States. 91.38\% (Figure 14) of the students said that they feel fulfilled every day in the United States.

On one hand, they feel worried and troubled by the various difficulties and challenges encountered in their studies, daily life and interpersonal communication; on the other hand, they are happy for their growing up under pressure in a foreign country and the gradual improvement of their abilities in all aspects.

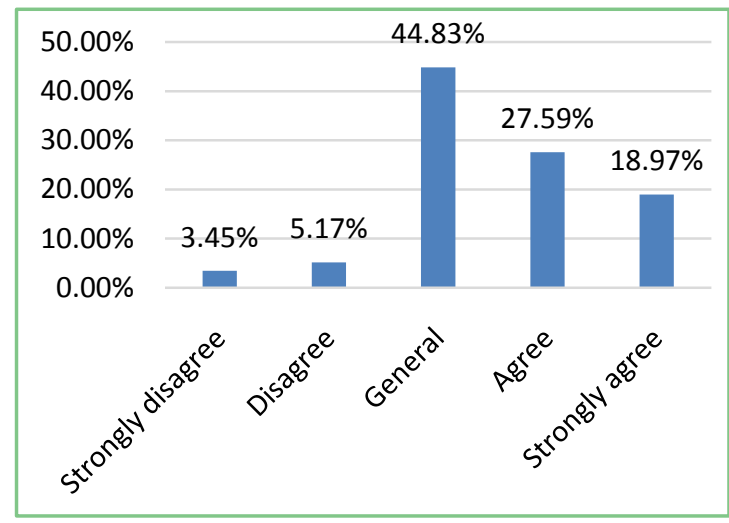

Figure 13. I feel happy every day in the United States. 


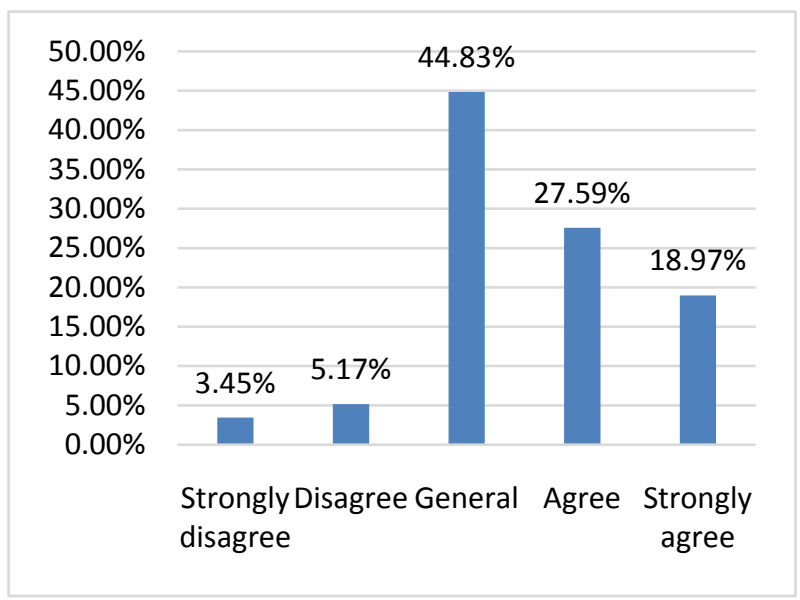

Figure 14. I feel fulfilled every day in the United States.

When talking about the gains from studying abroad, what students talk about most is the improvement of personal abilities and self-growth, especially the significant improvement in independence. In general, the personal gains mentioned by the interviewed students mainly include four aspects: language improvement, academic achievement, personal ability improvement and self-growth, as well as professional knowledge learning and foreign cultural experience.

\section{Suggestions for Improving Cross-Cultural Adaptability}

The researchers combine work experience and research results to put forward suggestions to help students in future study abroad training programs in improving the domestic curriculum, enhancing students' self-efficacy in cross-cultural adaptation, cultivating students' self-adaptability, and for parents of international students.

\subsection{Optimize Curriculum Settings and Clarify Training Objectives}

During the first two years of domestic study, students should systematically study the history and culture of the destination country. Chinese students only need to study and understand the country's history in order to understand their culture. This not only requires students to master the common language of the country they are going to, but also needs them to understand the local culture and cultural roots and understand the uniqueness of the destination country. The characteristics of national spirit arise from the historical background.

\subsection{Use Situational Teaching Mode to Create a "Quasi-Natural" Oral Training Scene}

In terms of language adaptation, speaking and writing are two important points for studying and living abroad, and oral training should be appropriately increased. In seminar, the quality and frequency of students' speeches are the conditions for judging the students' academic ability. Due to the influence of traditional cultural thoughts such as humility and moderation, Chinese students are generally more reserved and will not take the initiative to speak. It is necessary to 
adjust the psychological status of students "fear of being laughed at" through the creation of oral training scenarios. In fact, compared with international students from other language-based countries, most Chinese international students who have received college education have better oral and expression skills in English. Language is essentially a tool of communication. Students' reluctance to discuss in the classroom not only affects the course performance, but also hinders the communication between students and teachers. It is very important to cultivate the awareness and ability of Chinese students who dare to speak and speak boldly (Fang, 2010).

\subsection{Moderately Increase Opportunities for Teamwork and Increase the Reading Range of Textbooks}

American universities generally focus on teamwork and train students in the process of learning to organize, coordinate, manage, communicate, and cooperate. Chinese students should be familiar with the teaching methods of American universities in advance. In addition to cultivating students' academic learning ability, team leadership must also be cultivated. Student leaders must be consciously trained to become a responsible management and leadership team. In addition to showing themselves academically, students can communicate, coordinate, organize and arrange division of labor among team members. Through various means of communication, it finally becomes the team members working together in the same direction.

\subsection{Lower Expectations for Life Abroad}

Chinese students' understanding of American life mainly comes from European and American film and television works. After arriving in the United States, students will find that the city where their university is located is far from the bustling and lively life of New York, Miami, Los Angeles and other big cities in the film and television works. Studying abroad life is simple, monotonous and lonely. Students suddenly move from a large Chinese city with a dense flow of people and a colorful life to a small foreign town that is quiet and sparsely populated, and they will feel a greater psychological gap. Researchers suggest that universities and families need to guide students to adjust their cognition and make it clear that the task of studying abroad is to study, not to experience life in a prosperous international metropolis. It is possible to set up cultural introduction courses to fully introduce the real situation in the United States in sub-projects, to understand the actual situation of life in small towns in the United States in advance, and to reduce students' expectations of life in the United States before going abroad (Huang, 1994).

\subsection{Cultivate Life Skills and Enhance the Happiness of Studying Abroad}

The food in the United States is mostly pasta and dairy products. Most Chinese students did not adapt to the local food when they first arrived in the United 
States. Mixed with factors such as climate, water and soil, and food cooking methods, Chinese students would get angry after eating lots of burgers and pizzas. However, most students knew very little about buying food and cooking before going abroad. After arriving in the United States, they had no choice but to cook by themselves, so they felt particularly uncomfortable with their diet. For international students who are about to go abroad, parents should systematically and teach their children to buy and cook, and learn to cook simple and delicious meals. Students are suggested to establish a sense of self-management life independent from parents, learn to cook, and learn to take care of themselves in all life aspects. Taking care of daily life as a necessary life skill is a guarantee to improve life satisfaction after studying abroad.

\section{Conclusion}

After Chinese students fully understand the American social culture and educational model, they will take the initiative to make positive individual behavior adjustments. They must focus on adopting cross-cultural integration strategies, absorbing the excellent cultural elements of the United States and China, and discarding its dross. It's suggested that they actively step out of the internalized Chinese cultural model and education model, and adapt to the academic and cultural concepts of American universities. This will help Chinese students relieve cross-cultural pressure and shorten the period of cross-cultural adaptation. Generally speaking; students have improved in the following areas after entering the United States.

\subsection{Personal Ability Improvement and Self-Growth}

Students studying in the United States have improved their independent living ability, cross-cultural adaptability, self-control, time management ability, and critical thinking ability, as well as their personal maturity and self-confidence.

\subsection{Professional Knowledge Learning and Foreign Cultural Experience}

In terms of professional skills and cultural knowledge, the students said that studying abroad has given them a deeper and more accurate understanding and understanding of American social culture, oral presentation skills, cross-cultural communication skills, academic English writing skills, management skills, and their teamwork ability has been greatly improved.

\subsection{Language Improvement}

There have been improvements in all aspects of English listening, speaking, reading and writing, the most obvious of which is the improvement of oral and writing skills, and it also has a certain role in promoting Chinese writing skills.

\subsection{Academic Achievement}

Students' academic achievements mainly include professional knowledge and 
foreign academic qualifications. Many students said that the successful completion of their studies to obtain a degree affirms their hard work, and also makes them more competitive in future career development.

\section{Funding}

This research is funded by the Special Innovation Project of Department of Education of Guangdong Province "Research on the Cultural Adaptability of the Trainees of the Articulation Program from the Perspective of the Belt and Road Initiative" (project number: 2016GXJK046). It is also a research report of Young Innovative Talent Cultivation Project in 2016 "Research on the Cultural Adaptability of the Trainees of the Articulation Program of Guangdong University of Foreign Studies from the Perspective of the Belt and Road Initiative" by Center for Foreign Literature and Culture of Guangdong University of Foreign Studies (project number: 16QNCX09).

\section{Conflicts of Interest}

The authors declare no conflicts of interest regarding the publication of this paper.

\section{References}

Eura, J., Michael, L. H., \& Brooke, C. W. (2007). The Role of Identity in International Students' Psychological Well-Being in the United States: A Model of Depression Level, Identity Gaps, Discrimination, and Acculturation. International Journal of Intercultural Relations, 31, 605-624.

Fang, Y. (2010). An Empirical Study on the Status Quo, Influencing Factors and Strategies of International Students' Cultural Adaptation. Journal of Inner Mongolia Normal University (Education Science Edition), 23, 39-42.

Huang, X. (1994). Discussion on the Adaptability of Contemporary Chinese Student Groups. Educational Research, No. 11, 42-46.

Lewthwaite, M. (1997). A Study of International Students' Perspectives on Cross-Cultural Adaptation. International Journal for the Advancement of Counselling, 19, 167-185.

Tan, Y. (2013). Research on the Cross-Cultural Adaptation of Students in Sino-Foreign Cooperation in Running Schools in Universities. Beijing: Central University for Nationalities.

Wang, Y. (2012). Analysis of Chinese Students Studying Abroad and Cultural Adaptability. Anhui Literature (the Second Half of the Month), No. 7, 148-150.

Xie, J. (2013). Investigation on the Motivation and Adaptability of University Students to Study Abroad at Their Own Expense. Chengdu: University of Electronic Science and Technology of China.

Yan, K. (2011). Chinese International Students in the United States: Cross-Cultural Adjustment and Challenges. Educational Research of Tsinghua University, 32, 100-109.

Zhou, Y., \& Todman, J. (2009). Patterns of Adaptation of Chinese Postgraduate Students in the United Kingdom. Journal of Studies in International Education, 13, 467-486. 